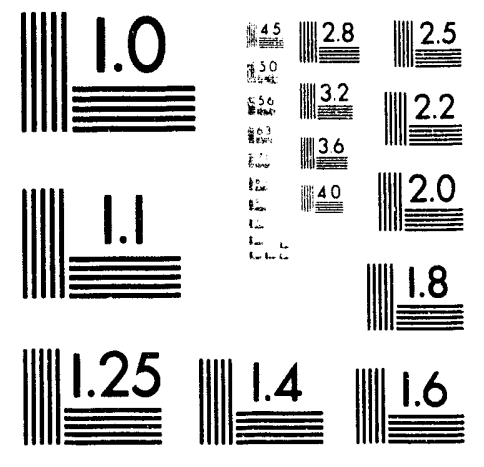



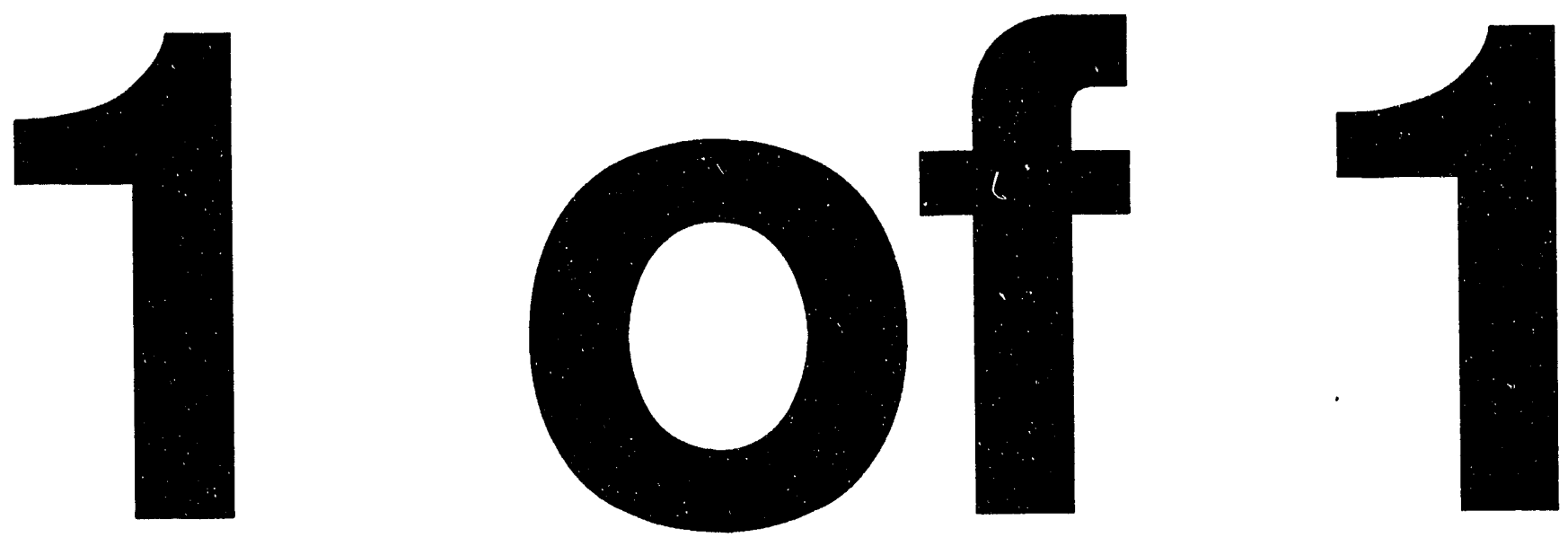


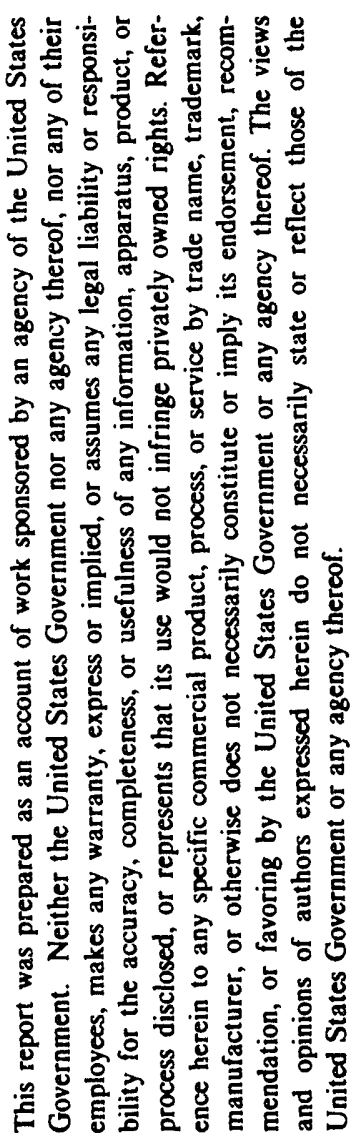

\section{SHOCK-LOADING RESPONSE OF ADVANCED MATERIALS}

Submitted to:

Author(s):

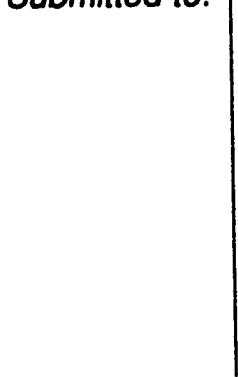

Los Alamos

NATIONAL LABORATORY

\author{
APS Topical Conference on Condensed Matter \\ June 28 - July 2, 1993 \\ Colorado Springs, CO \\ Invited Talk
}

G. T. Gray
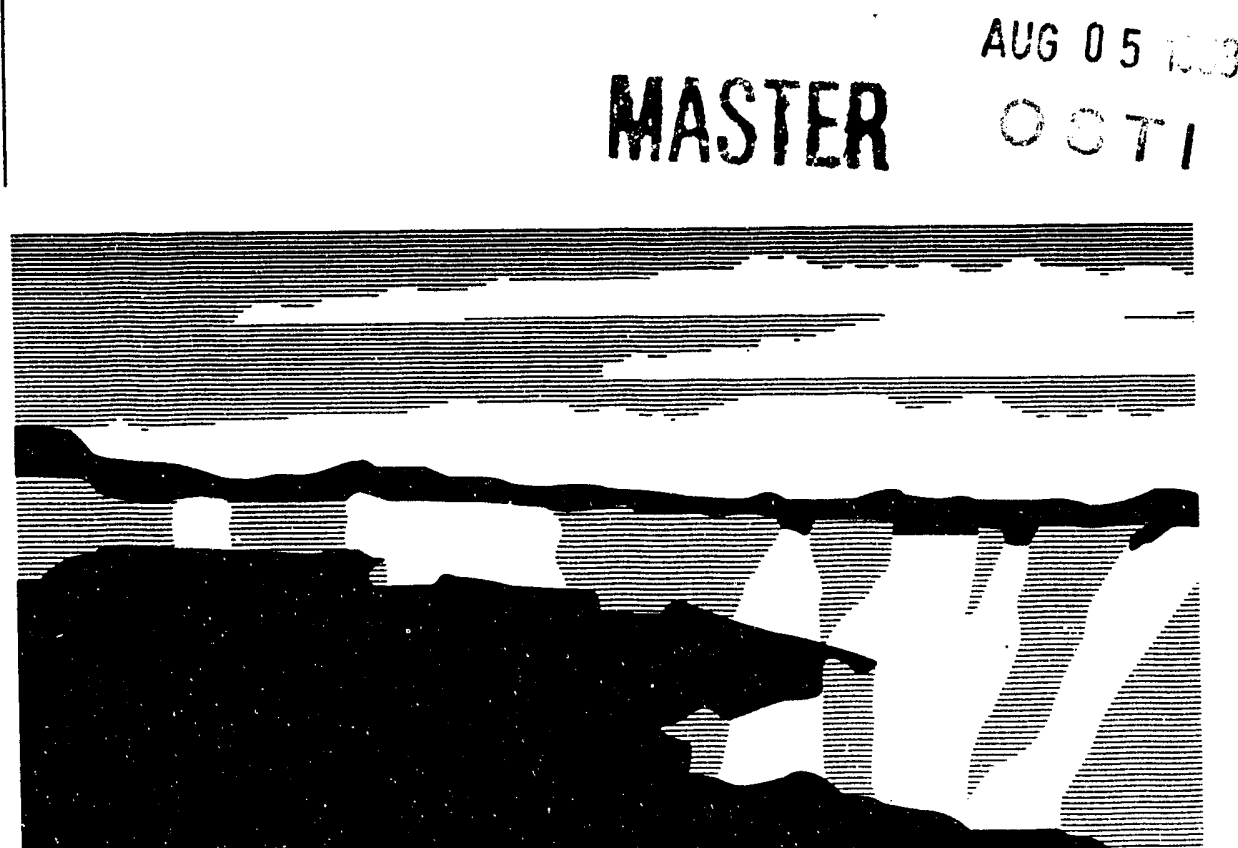

Los Alamos National Laboratory, an aftirmative action/equal opportunity empldyer, is operated by the University of California for the U.S. Department of Energy Los Alamos National Laboratory, an aftirmative action/equal opportunity employer, is operated by the University of Callorist under contract W-7405-ENG-36. By acceptance of this article, the publisher recognizes that the U.S. Government retains a nonexclusive, royalty-free license requests that the publisher identify this article as work performed under the auspices of the U.S. Department of Energy. 


\title{
SHOCK-LOADING RESPONSE OF ADVANCED MATERIALS
}

\author{
G. T. Gray III \\ Los Alamos National Laboratory \\ Los Alamos, New Mexico, USA 87545
}

Advanced materials, such as composites (metal, ceramic, or polymer-matrix), intermetallics, foams (metallic or polymeric-based), laminated materials, and nanostructured materials are receiving increasing attention because their properties can be custom tailored to specific applications. The high-rate/impact response of advanced materials is relevant to a broad range of service environments such as the crashworthiness of civilian/military vehicles, foreign-object-damage in aerospace, and light-weight armor. Increased utilization of these material classes under dynamic loading conditions requires an understanding of the relationship between high-rate / shock-wave response as a function of microstructure if we are to develop models to predict material behavior. In this paper the issues relevant to defect generation, storage, and the underlying physical basis needed in predictive models for several advanced materials will be reviewed.

\section{INTRODUCTION}

Advanced materials, such as composites (metal, ceramic, or polymer-matrix), laminated materials, intermetallics, nanostructured materials, and foams (metallic or polymeric-based) are receiving increasing attention due to their tailor-able properties. These include higher specific strengths, stiffnesses, and high temperature properties. Composites and laminated materials also allow other physical properties besides mechanical properties to be custom designed to specific applications. The high-rate/impact response of advanced materials is relevant to a broad range of service environments such as the crash-worthiness of civilian/military vehicles, foreign-object-damage in aerospace applications, and light-weight armor. Increased utilization of these material classes under dynamic loading conditions requires an understanding of the relationship between high-rate / shock-wave response as a function of microstructure if we are to develop constitutive models to predict material behavior.

In contrast to single-phase materials, composites, laminates, and ordered intermetallics are: 1) heterogeneous mixtures (either a particulate or continuous second-phase, layered, woven, laminated, etc. composite or a structurally ordered matrix), 2) elastically and plastically anisotropic, and 3) achieve some of their properties due to interfacial effects that influence the plastic flow and fracture behavior. These three attributes can cause a broad range of effects on the structure/property relationships of composites and intermetallics subjected to shock loading. Increasing utilization of 'advanced materials' in future engineering designs will necessitate a fundamental understanding of how the deformation response these ordered or complex multi-phase structures accommodate high-rate plastic deformation. In this paper the issues relevant to defect generation, storage, and the underlying physical basis needed in predictive models for several advanced materials will be discussed.

\section{EXPERIMENTAL}

Shock recovery experiments were performed on two composites and one intermetallic compound with an $80-\mathrm{mm}$ single-stage launcher utilizing recovery techniques as described previously[1]. $\mathrm{Cu}-15$ vol.\% Nb, 6061-T6-10 vol.\% $\mathrm{Al}_{2} \mathrm{O}_{3}$, and polycrystalline $\mathrm{Ni} 3 \mathrm{Al}$ samples were shock loaded in symmetric shock-recovery assemblies for $1 \mu \mathrm{s}$ pulse durations to various shock peak pressures. The $\mathrm{Cu}-\mathrm{Nb}$ represents a ductile metal-matrix composite exhibiting good interfacial strerigth 
and based on negligible solid-solution solubility of each metal in the other. Aluminum-alumina composites are available with a wide range of reinforcement volume fractions, second-phase morphologies, and second-phase sizes. Figure 1 shows examples of two 6061-T6-Al2 33 with two different particulate sizes and shapes at a nominally constant second-phase volume fraction of 10 vol.\%. Ni3Al represents an orderedfcc(L12) intermetallic compound. Compression samples were EDM machined from the asreceived and shock-recovered $\mathrm{Cu}-\mathrm{Nb}, 6061$-T6$\mathrm{Al}_{2} \mathrm{O}_{3}$, and $\mathrm{Ni3} \mathrm{Al}$ samples, and reloaded at a strain rate of $0.001 \mathrm{~s}^{-1}$ at $298 \mathrm{~K}$.

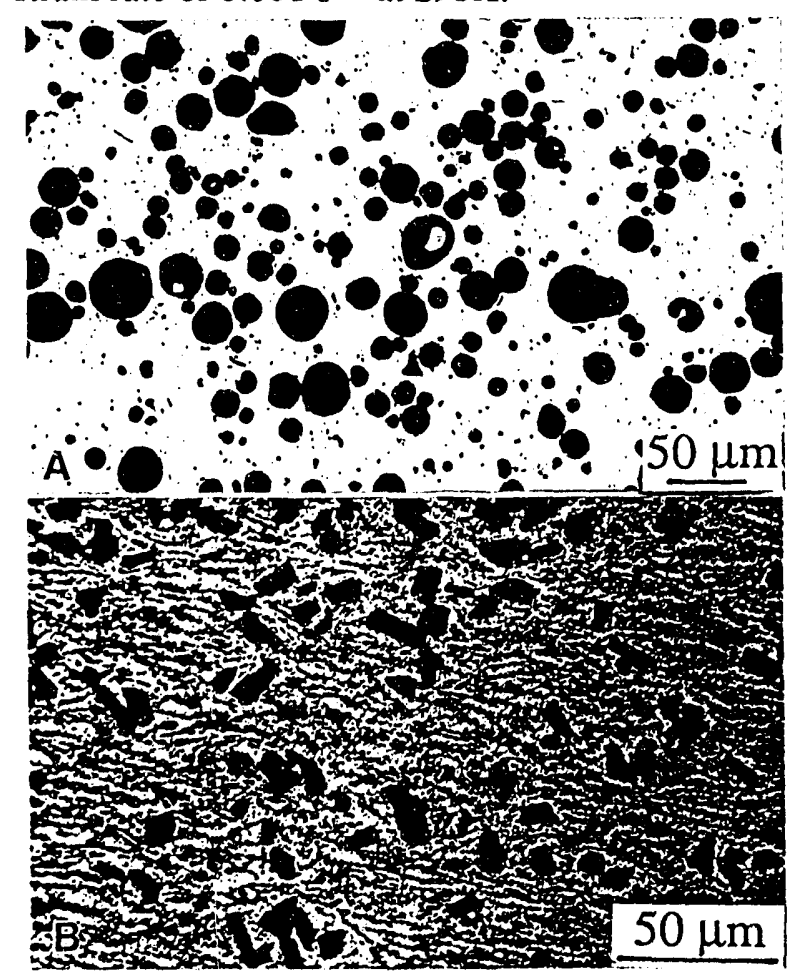

Figure 1. Optical micrograph of two 6061-T6 Al10 vol. $\% \mathrm{Al}_{2} \mathrm{O}_{3}$ particulate composites with: a) spherical particles, and b) irregular particles of two different particle sizes.

\section{RESULTS AND DISCUSSION}

The $\mathrm{Cu}-\mathrm{Nb}$ and 6061-T6- $\mathrm{Al}_{2} \mathrm{O} 3$ composites were selected to examine the influence of particulate metal and ceramic-phase additions on material shock response. The $\mathrm{Cu}-\mathrm{Nb}$ composite represents a ductile second-phase reinforcement where: a) both phases have similar sound speeds of $\sim 4$ $\mathrm{km} / \mathrm{s}$, and b) both phases are expected to deform at low shock pressures ( $<10 \mathrm{GPa})$. The 6061-T6$\mathrm{Al}_{2} \mathrm{O}_{3}$ case contrarily represents a composite where: a) the reinforcement sound speed is $\sim 2 x$ faster than that of the matrix, and $b$ ) at low shock pressures the $\mathrm{Al}_{2} \mathrm{O}_{3}$ will remain elastic while the matrix will readily plastically deform. Differences in shock velocity are known to influence the dispersive effects of the composite and thereby significantly change the loading and release wave profiles[1]. Systematic studies are crucial to enable modeling of how different composite reinforcement types (particulates, disks, rods), volume fractions, morphologies, etc. affect wave dispersion.

The quasi-static and shock response of the $\mathrm{Cu}-\mathrm{Nb}$ composite and single-phase pure copper is shown in Figure 2. The $\mathrm{Cu}-\mathrm{Nb}$ is observed to possess a higher quasi-static yield strength but after $\sim 10 \%$ strain to exhibit a similar work-hardening rate. The reload $\mathrm{Cu}-\mathrm{Nb}$ is also seen to exhibit a fall off in the reload response after yielding rather than sustained hardening. The reload shock curves in Figures 2 have been offset with respect to the annealed responses at low-strain rate by the transient strain generated by the shock defined as $4 / 3 \ln \left(V / V_{O}\right)$, where $V$ and $V_{o}$ are the final and initial volumes of $\mathrm{Cu}$ during the shock cycle. Pure $\mathrm{Cu}$ is seen to exhibit enhanced shock hardening compared to $\mathrm{Cu}$ deformed quasistatically to an equivalent strain level.

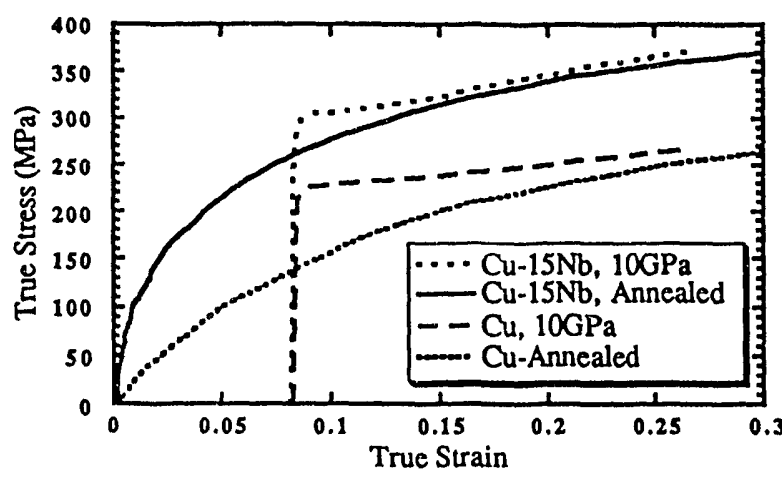

Figure 2. Reload stress-strain response of shockloaded $\mathrm{Cu}-\mathrm{Nb}$ composite and $\mathrm{Cu}$ compared to that observed during quasi-static deformation for each material. 
While the $\mathrm{Cu}-\mathrm{Nb}$ composite has an increased reload yield strength compared to its quasi-static response it does not exhibit the pronounced shock-hardening of pure $\mathrm{Cu}$. At a true strain of 0.15 the annealed and shock reload responses of the $\mathrm{Cu}-\mathrm{Nb}$ are coincident while the shocked $\mathrm{Cu}$ curve displays increased flow stress levels over the annealed $\mathrm{Cu}$ until a strain of 0.25 . Defect generation and storage in the $\mathrm{Cu}-\mathrm{Nb}$ composite represents a combination of bcc and fcc materials with each possessing drastically different strainrate and temperature sensitivities. $\mathrm{Nb}$, due to its high inherent lattice resistance (Peierls Stress) under high-rate or shock loading will possess a much higher flow stress than copper thereby acting more "elastic" until higher stress levels are reached. This process might be expected to store a disproportionate amount of the defects in the $\mathrm{Cu}$ matrix. Upon quasi-statically reloading the shock-recovered composite sample the $\mathrm{Nb}$ now finds itself with a lower inherent flow stress surrounded by a highly work-hardened $\mathrm{Cu}$ matrix. This process will tend to reduce the total defect storage in the $\mathrm{Cu}-\mathrm{Nb}$ and result in an unstable state in the $\mathrm{Nb}$ which is consistent with the slight yield fall off in the reloaded shock $\mathrm{Cu}$ $\mathrm{Nb}$ sample.

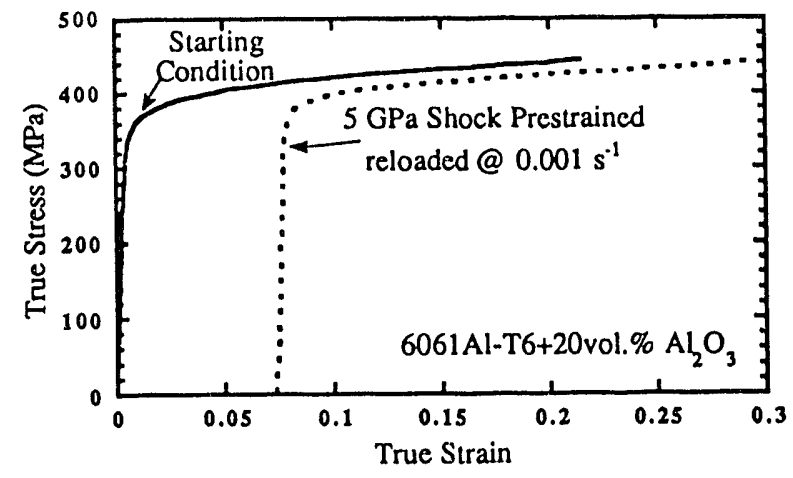

Figure 3. Reload stress-strain response of 6061T6- $\mathrm{Al}_{2} \mathrm{O}_{3}$ composite shock prestrained to $5 \mathrm{GPa}$ offset to the quasi-static starting material.

The shock-response of the 6061-T6 Al - 10 vol.\% $\mathrm{Al}_{2} \mathrm{O}_{3}$ composite is substantially different than the $\mathrm{Cu}-\mathrm{Nb}$ discussed so far(Figure 3 ). Similar to previous observations on a shock-loaded $\mathrm{Al}-\mathrm{Zn}$ -
$\mathrm{Mg}-\mathrm{Cu}$ alloy-SiC composite $[3,4]$ the reload stress-strain response of the shocked $6061-\mathrm{Al}_{2} \mathrm{O}_{3}$ is lower than the quasi-static stress-strain curve. At first glance this behavior seems inconsistent with the fact that: a) at low strains during quasistatic loading many particulate-ceramic composites exhibit anomalously high apparent work hardening rates due to load transfer to the reinforcement, b) with the imposition of a hydrostatic stress or testing in compression the process of damage accumulation is suppressed and these composites exhibit continued hardening and enhanced ductility[5]. These facts might suggest that we would expect substantial shock hardening of ceramic-reinforced composites.

However, in the shock process, contrary to a uniaxial test, deformation encompasses a stress and strain path reversal during the compressive loading and release[3]. The lower reload yield stress in shock-loaded hard-second-phase composites is therefore consistent with a Bauschinger effect[3] in two-phase materials. The Bauschinger effect in the reloaded shock samples is manifested in lower yield behavior after the strain-path reversal inherent in the shock and caused by the back stresses built up during the shock release.

Ordered compounds represent an exciting challenge to our understanding and modeling of defect generation and storage during shock loading. To prevent local disordering of the structure dislocations in many ordered compounds move in linked pairs which disorder and reorder the lattice as the superdislocation moves. Dislocation motion in most ordered intermetallics is accompanied by a large Peierls stress which results in a high temperature and strain-rate sensitivity. Coincident with the restriction of dislocation motion in pairs is the difficulty of dislocation cross-slip to other slip planes.

An important engineering intermetallic that is an exception to many of these properties is $\mathrm{Ni3} \mathrm{Al}[6]$. Ni3 Al displays a low temperature and rate-sensitivity similar to annealed fcc metals due to a low Peierls barrier to $\{111\}<110>$ dislocations. The shock response of $\mathrm{Ni3} A l$ 
contrasted to pure $\mathrm{Ni}$ is shown in Figure 4. $\mathrm{Ni} 3 \mathrm{Al}$ is seen to display an enhanced hardening response compared to its quasi-static hardening behavior to an equivalent strain level.

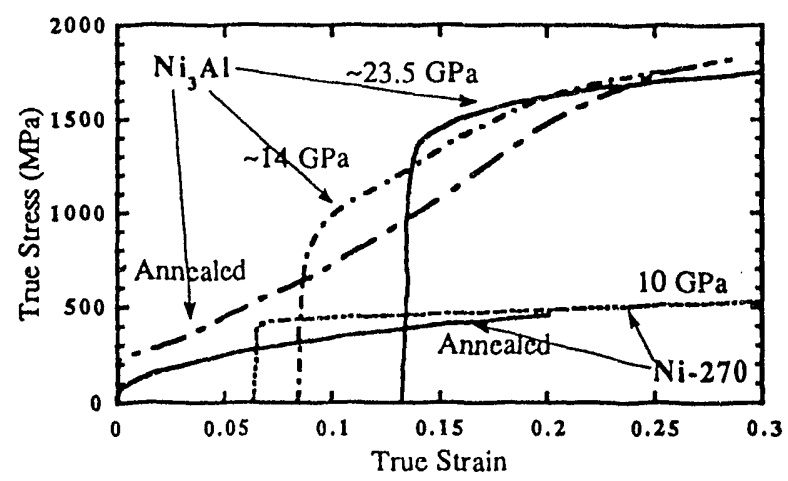

Figure 4. Reload stress-strain response of shockloaded $\mathrm{Ni3} \mathrm{Al}$ and $\mathrm{Ni}$ compared to that observed during quasi-static deformation.

While it is difficult to compare the behavior of shocked Ni3Al with shocked Ni several insightful observations are evident from such a comparison. In a simplistic sense this can be considered in terms of a very high value of the saturation stress, ssat. In Ni3Al sustained hardening at quasi-static rates under ambient conditions is observed to stresses approaching $2 \mathrm{GPa}$ [7]. In contrast $\mathrm{Ni}$ exhibits a saturation stress, $i$ e, asymptotic saturation of the flow stress, at a stress level of approximately $450 \mathrm{MPa}$. Given the nearly identical elastic and shear modulii of $\mathrm{Ni}$ and $\mathrm{Ni} 3 \mathrm{Al}$ the approximarely $4 \mathrm{x}$ increase in the "saturation stress" between the two materials clearly demonstrates that drastically different dynamic recovery mechanisms are controlling the transition from Stage II to III in Ni3Al[7].

\section{SUMMARY AND CONCLUSIONS}

Indications of the shock generation and storage mechanisms operative in composites can be elucidated using shock-recovery studies of select composites. Given knowledge of the secondphase physical and mechanical properties, composites can be used as "internal markers" to allow an inside view of shock propagation and damage evolution throughout a material.
Systematic manipulation of the reinforcement from shearable particles to those possessing varying interfacial strengths and studying various ordered materials will provide considerable insight into defect generation and storage mechanisms in advanced materials.

\section{ACKNOWLEDGMENTS}

The author wishes to acknowledge C. Trujillo, W. Wright, and M.F. Lopez for their assistance with the experimental aspects of this study. This work was performed under the auspices of the U.S. Department of Energy.

\section{REFERENCES}

[1] G.T. Gray III, in High Pressure Shock Compression of Solids, (ed. by J.R. Asay and M. Shahinpoor) NY: Springer-Verlag, ch. 6, (1993).

[2] L.M. Baker, J. Comp. Matls., 5, pp. 140-162, (1971).

[3] G.T. Gray III, R.S. Hixson, and C.E. Morris, in Shock Comp. of Condensed Matter-1991, (ed. by S.C. Schmidt, R.D. Dick, J.W. Forbes, and D.G. Tasker) North-Holland (1992) pp. 427-430.

[4] S.I. Hong, G.T. Gray III, and J.J. Lewandowski, Scripta Metall., 27, pp. 431-436, (1992).

[5] J.D. Embury and G.T. Gray III, in Mod.of Plastic Def.and its Eng.Appl. (ed. by S.I. Andersen, J.B. Bilde-Sorensen, N. Hansen, D. Juul Jensen, T. Leffers, H. Lilholt, T. Lorentzen, O.B. Pedersen, and B. Ralph, Riso National Laboratory, Roskilde, Denmark (1992)pp. 39-56..

[6] H.W. Sizek and G.T. Gray III, Acta Metall. Mater., 41, pp. 1855-1860, (1993).

[7 ] G. T. Gray III and J. D. Embury, in High-Temp.Ord.Inter. Alloys-V ( ed. by I. Baker, R. Darolia, J.D. Whittenberger, and M.H. Yoo), MRS, Pgh., PA , (1993) vol. 288, pp. 585-590. 

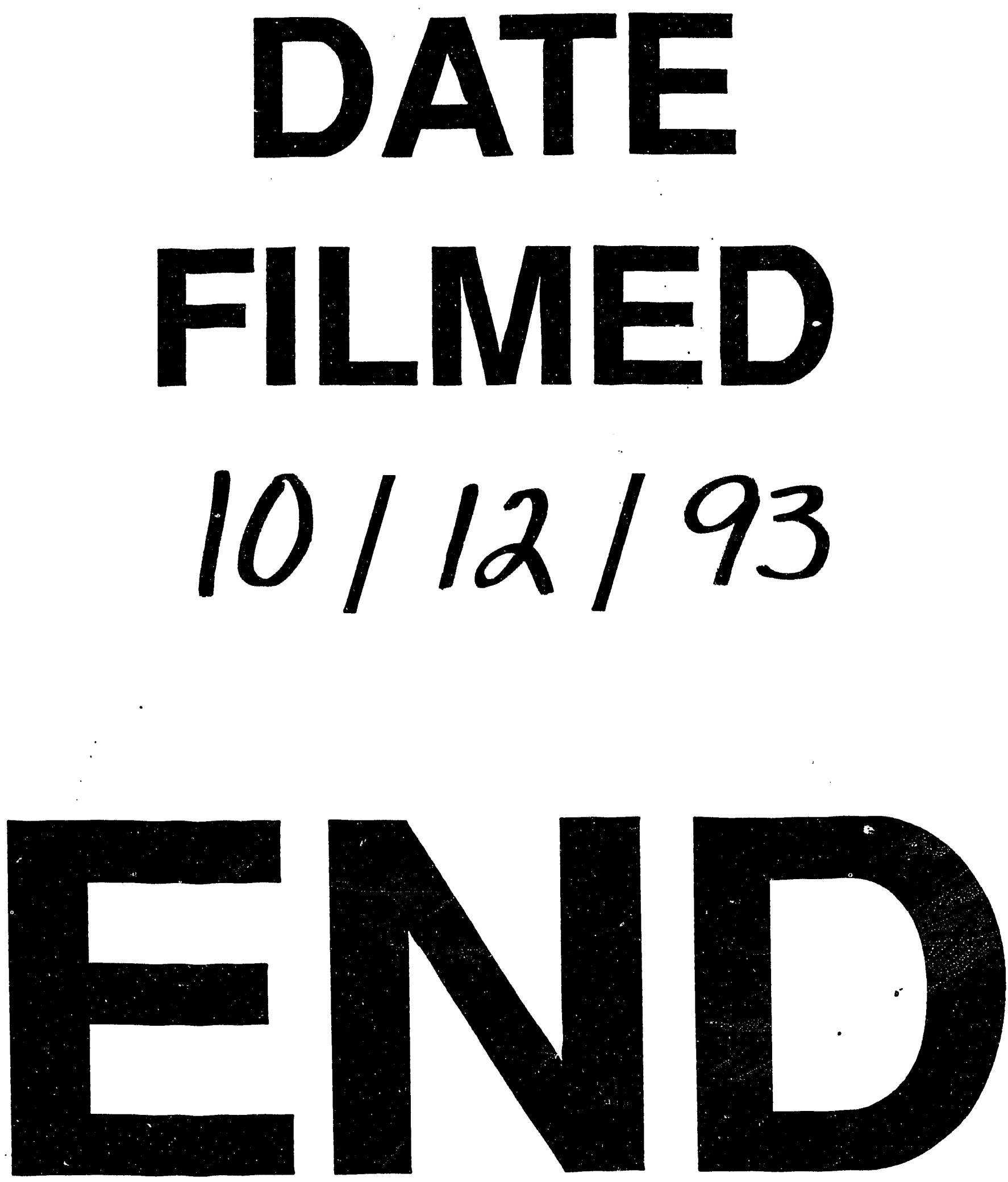
